\section{To: (Receiving Organization) \\ Distribution \\ 5. Proj./Prog./Dept./Div.: \\ Radiological Engineering \\ 8. Originator Remarks: and remote monitoring. \\ 11. Receiver Remarks: \\ 15.

\begin{tabular}{|l|l}
\hline $\begin{array}{c}\text { (A) } \\
\text { Item } \\
\text { No. }\end{array}$ & (B) Document/Drawing No. \\
\hline 1 & RPP-5152 \\
\hline & \\
\hline & \\
\hline & \\
\hline & \\
\hline
\end{tabular}

"Technical Basis for Implementation of Remote Reading Capabilities for Radiological Control Instruments at Tank Farms" is being issued as RPP-5152 to establish a basis for various uses of instumentation

11A. Design Baseline Document? $\bigcirc$ Yes

O No
RPP Radiological Control

6. Design Authority/Design Agent/Cog. Engr.:

R. L. Brown
DATA TRANSMITTED

(C) Sheet (D) Rev.

\begin{tabular}{l|l} 
No. & No. \\
\hline
\end{tabular}

\begin{tabular}{l|l}
$\mathrm{N} / \mathrm{A}$ & 0
\end{tabular}

Technical Basis for

Implementation of Remote

Reading Capabilities for
4. Related EDT No::

$\mathrm{N} / \mathrm{A}$

7. Purchase Order No:

$\mathrm{N} / \mathrm{A}$

9. Equip./Component No.:

$\mathrm{N} / \mathrm{A}$

10. System/Bldg./Facility:

RPP

12. Major Assm. Dwg. No.:

$\mathrm{N} / \mathrm{A}$

13. Permit/Permit Application No.:

$\mathrm{N} / \mathrm{A}$

14. Required Response Date

$\mathrm{N} / \mathrm{A}$
16.

Approval Designator (F)

E, S, Q, D OR N/A (See WHC-CM-3-5, Sec. 12.7)

17

(G)

\begin{tabular}{|c|c|c|}
\hline $\begin{array}{l}\text { (G) } \\
\text { Rea- } \\
\text { son }\end{array}$ & $\begin{array}{c}(\mathrm{H}) \\
\text { Disp. }\end{array}$ & (J) Name \\
\hline & & Design Authority $\mathrm{N} / \mathrm{A}$ \\
\hline & & Design Agent $\mathrm{N} / \mathrm{A}$ \\
\hline 1 & 1 & Cog. Eng. R. I, E \\
\hline 1 & 1 & Cog. Mgr. J. W. \\
\hline & & $\mathrm{N} / \mathrm{A}$ \\
\hline & & Safety \\
\hline & & $\mathrm{N} / \mathrm{A}$ \\
\hline $\begin{array}{l}18 . \\
\text { R. } \\
\text {. }\end{array}$ & $\mathrm{P}$ & $\begin{array}{l}\text { Jisnew ws } \\
\text { erson }\end{array}$ \\
\hline & ure o & Date \\
\hline
\end{tabular}

(K) Signature
1. Approval

3. Intormation
(E) Title or Description of Data Transmitted

RadCon Inst. at Tank Farms
(F)

App

\begin{tabular}{|c|c|c|}
\hline$(\mathrm{G})$ & $(\mathrm{H})$ & $(\mathrm{l})$ \\
\hline $\begin{array}{c}\text { Reason } \\
\text { for Trans- } \\
\text { mittal }\end{array}$ & $\begin{array}{c}\text { Origi- } \\
\text { nator } \\
\text { Oispo- } \\
\text { stion }\end{array}$ & $\begin{array}{c}\text { Receiv- } \\
\text { er } \\
\text { Dispo- } \\
\text { sition }\end{array}$ \\
\hline 3 & 1 & \\
\hline & & \\
\hline & & \\
\hline & & \\
\hline
\end{tabular}

KEY

Reason for Transmittal (G)
4. Review
5. Post-Review
6. Dist. (Receipt Acknow. Required)

SIGNATURE/DISTRIBUTION
(See Approval Designator for required signatures)

\begin{tabular}{|ll}
$|c|$ & Disposition $(H) \&(I)$ \\
$\begin{array}{ll}\text { 1. Approved } & \text { 4. Reviewed no/comment } \\
\text { 2. Approved w/comment } & \text { 5. Reviewed w/comment } \\
\text { 3. Disapproved w/comment } & \text { 6. Receipt acknowledged }\end{array}$ \\
\hline
\end{tabular}
(L) Date (M) MSIN
(K) Signature
(L) Date
(M) MSIN

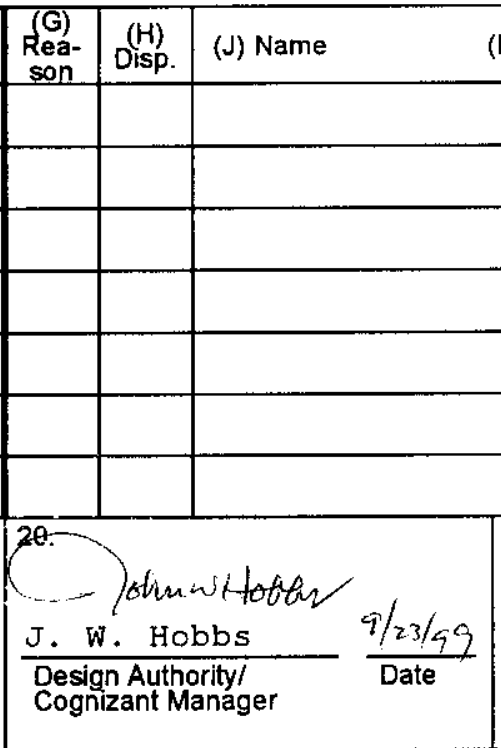

R. H. Lizfetet Authorized Refresentative for Receiving Organization

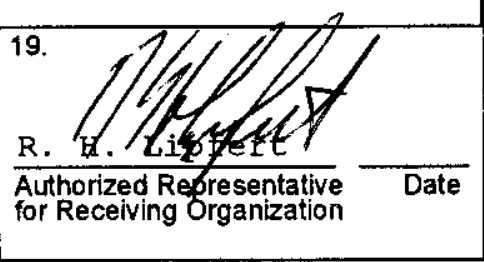

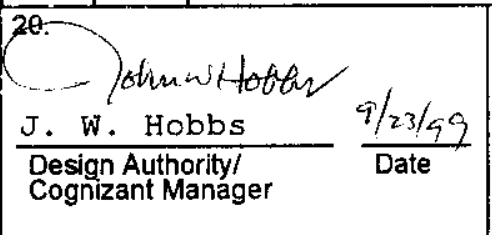

21. DOE APPROVAL (if required)

Ctrl No. N/A

Approved

Approved w/comments

Disapproved w/comments 


\title{
Technical Basis for Implementation of Remote Reading Capabilities for Radiological Control Instruments at Tank Farms
}

\author{
R. M. Pierson \\ LockHeed Martin Hanford Corporation \\ Richland, WA 99352 \\ U.S. Department of Energy Contract DE-AC06-96RL13200
EDT/ECN: $E D T-627776 \quad$ UC: 2080
Org Code: $79700 \quad$ Charge Code: 102586
B\&R Code: N/A Total Pages: 7 \\ Key Words: River Protection Project; ALARA; Instruments
}

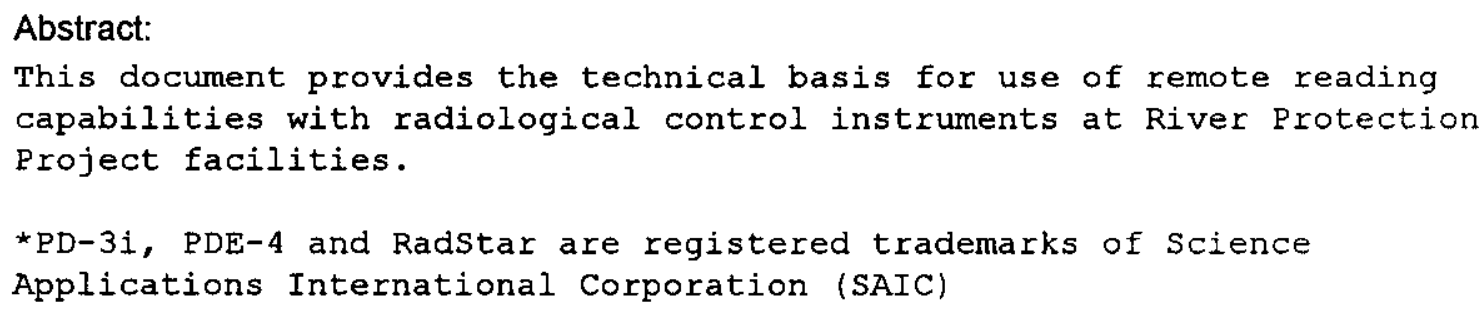

TRADEMARK DISCLAIMER. Reference herein to any specific commercial product, process, or service by trade name, trademark, manufacturer, or otherwise, does not necessarily constitute or imply its endorsement, recommendation, or favoring by the United States Government or any agency thereof or its contractors or subcontractors.

Printed in the United States of America. To obtain copies of this document, contact: Document Control Services, P.O. Box 950, Mailstop H6-08, Richland WA 99352, Phone (509) 372-2420; Fax (509) 376-4989.
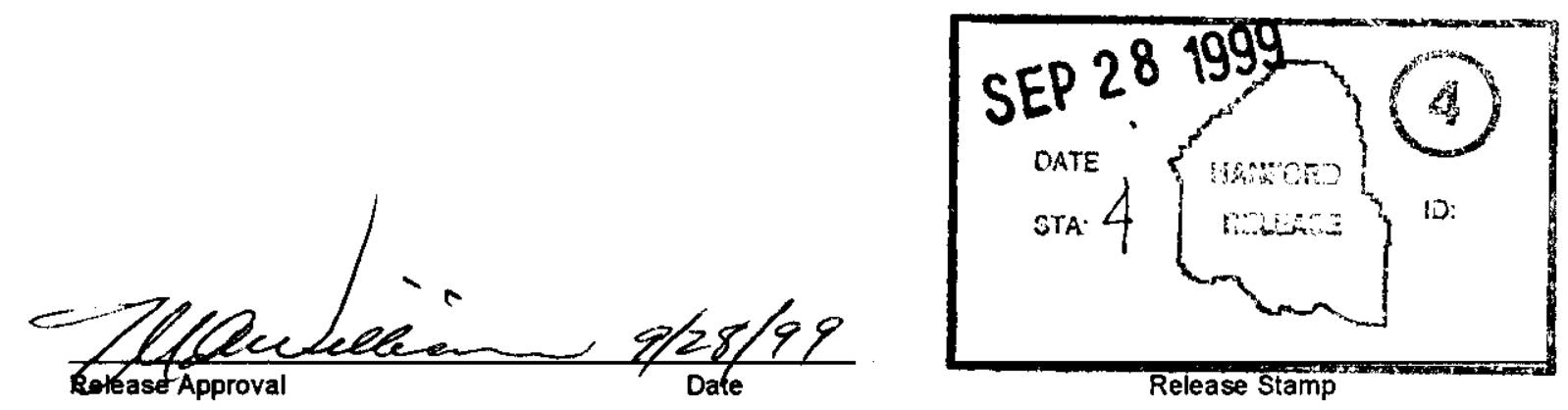

\section{Approved For Public Release}




\subsection{Purpose}

The purpose of this document is to evaluate applications of remote reading capabilities with Radiological Control instrumentation to allow continuous monitoring of radiation dose rates at River Protection Project (RPP) facilities. In addition this document provides a technical basis and implementing guidelines for remote monitoring of dose rates and their potential contribution to maintaining radiation exposures ALARA.

\subsection{Scope}

This document does not provide the technical basis for determining the equivalency for remote monitoring to direct monitoring using hand-held instruments for contamination detection purposes. Contamination detection capabilities for personnel surveys are contained in TBTN: INGH-9503-RLS-0016 ${ }^{1}$. It applies only to the use of portable radiological instrumentation (including electronic dosimeters) in a remote capacity for the purpose of monitoring changes in radiation dose rates.

\subsection{Criteria and Requirements}

3.1 Monitoring of radiation dose rates is required to detect changes in levels of radiation.

10 CFR 835 , “Occupational Radiation Protection” \& 835.401.a.(3) and (6) state:

"Monitoring of individuals and areas shall be performed to detect changes in radiological conditions;" and "Identify and control potential sources of individual exposure to radiation and/or radioactive material."

3.2 Instruments used for monitoring radiation dose rates must be appropriate for their intended use.

\$ 835.401.b.(2)-(4), state: "Instruments and equipment used for monitoring shall be appropriate for the type(s) levels, and energies of the radiation(s) encountered; appropriate for existing environmental conditions; and routinely tested for operability."

3.3 Radiation exposures shall be maintained As Low As Reasonably Achievable (ALARA).

$\$ 835.1001$, states in part: "Measures shall be taken to maintain radiation exposure in controlled areas ALARA...."

The Hanford Site Radiological Control Manual (HSRCM-1) Article 311, states:

"Technical requirements for the conduct of work, including construction, modifications, operations, maintenance and decommissioning, shall incorporate radiological criteria to ensure safety and maintain radiation exposures ALARA. The primary methods used to maintain exposures ALARA shall be facility and equipment design features. These features may be augmented by administrative and procedural

\footnotetext{
'Ottley, 1994
} 
requirements. To accomplish this, the design and planning processes should incorporate radiological considerations in the early planning stages. The checklist in Appendix $3 \mathrm{~A}$ is helpful in reducing occupational radiation exposure."

The Hanford Site Radiological Control Manual (HSRCM-1) Appendix 3A Checklist for Reducing Occupational Radiation Exposure directs the performance of as much work as practicable outside radiation areas, consideration of special tools and keeping excess personnel out of radiation areas. The HSRCM-1, Article 562.1 states in part: "Radiological instruments shall be used only to measure radiation for which their calibrations are valid...."

3.4 Based on these criteria, the utilization of remote monitoring capabilities with portable radiological instrumentation can significantly reduce time in radiation areas and is consistent with ALARA requirements and philosophy.

\subsection{Baseline Determinations}

To ensure that the utilization of remote reading capabilities for radiological monitoring is consistent within the scope of this evaluation the following determinations are established as applicable to all field implementation activities.

4.1 A comparison of instrument performance capabilities against the variable remote monitoring capability aspects has not been performed and is beyond the scope of the current instrumentation approvals established by the Hanford Instrument Evaluation Committee (HIEC). In addition, it would be cost prohibitive to perform a separate evaluation or calibration on instruments as discussed in sections 4.1.1 and 4.1.2 below.

4.1.1 HSRCM Article H561.1 states: "Until DOE establishes a formal evaluation and testing program, selection of portable instruments used at Hanford should be based on recommendations of the HIEC and approved by the manager of the Hanford Instrument and Calibration and Evaluation Program."

4.1.2 HSRCM Article 562.6 states: "In unusual and limited situations it may be necessary to use an instrument in an application other than that envisioned by the manufacturer. Special calibrations should be performed for use of instrumentation outside manufacturer's specifications. The instrument shouid be adjusted, calibrated and labeled to identify the special conditions and used only under the special conditions for which it was calibrated."

4.1.3 HSRCM Article 551.5 states, "Instruments used to perform radiation surveys shall be readily available and response-checked daily or prior to operation. When response checks are not within \pm 20 percent of the expected value, the instrument should be taken out of service. When response checks are not feasible, such as with instruments used to measure neutrons or tritium, compensatory actions should be established to ensure proper instrument performance." 
4.2 The results obtained with radiological instruments utilizing remote reading capabilities are "qualitative" vice "quantitative" surveys.

4.2.1 For purposes of this document, Qualitative radiation survey means a survey for radioactivity that suggests whether the level of radioactivity might be less than or greater than some index such as a previous measurement or a reference value (a "go/no-go check"). The verification of how much a measurement is greater than or less than the index must be performed and documented with a quantitative measurement.

4.2.2 For purposes of this document, Quantitative surveys or measurements are those that are performed using proper instrumentation by individuals with the knowledge, skills, and experience necessary to ensure the required level of confidence in the measurements.

4.2.3 Only quantitative measurements shall be used to document radiological surveys performed to establish and monitor personnel radiological safety, such as radiological hold points or other surveys required by 10 CFR 835 or HSRCM-1. Qualitative measurements shall be used only to generally monitor progress of a work activity or detect the presence of a radiation field. If a qualitative measurement suggests the possibility of increased radiological hazards or exceeding some work limitations, work shall be stopped until a Radiological Control Technician (RCT) can verify and re-establish radiological conditions.

4.3 Instruments planned for use with remote monitoring should be functionally checked prior to initial use. Subsequent daily checks should be performed based on job specific evaluation of the ALARA considerations.

4.3.1 There has been a standard practice to use such instruments for "indication only" or qualitative readings. This practice can be used as an effective ALARA tool to give an indication of relative radiological conditions. The use of these instruments in this application is consistent with other indirect information about radiological conditions that is available from process monitoring information such as Area Radiation Monitors (ARMs), reactor power level, or $\mathrm{pH}$ level in process water.

4.3.2 Using "indication only" results as a "pre-survey" or "in-process" survey can be an effective ALARA tool, however the use of instruments with this approach is subject to limitations when the required compensatory actions are not established; these instruments may not be used as a sole indicator to perform radiological monitoring of radiation exposure, in order to:

- Characterize work place conditions,

- Verify the effectiveness of physical design features and engineering and administrative controls, or

- Identify areas requiring radiological postings. 
These survey results may be used to determine optimum ALARA approaches to work activities or used as single data points in time to track the radiological status of components during planned evolutions.

4.3.3 Characterization of workplace conditions as mentioned in Article 551.1, means performing and documenting radiological surveys in support of work activities (RCT's performing radiological surveys characterize their workplace "as they go" with portable hand-held radiation detection instrumentation).

Instrumentation results of this kind may never be used to determine personnel stay-times, set other administrative controls, or to determine radiological posting requirements; they may only be used to furnish preliminary or supplemental information on relative dose rates during the workplace characterization process. Dose rates from these applications should not be recorded on Radiological Survey Report forms unless there is a clear notation that the results are qualitative in nature.

\subsection{Implementation}

Prior to initial implementation of this evaluation and technical basis the following protocol is established to meet the commitment of ECR 2-7 Action $1.4 \mathrm{~h}^{2}$.

\subsection{Communication}

This change must be clearly communicated to personnel. The primary mechanism for this will be as follows:

- Written notification in memo format to HPT supervision on the subject.

- HPT training sessions on the subject within the facilities.

\subsection{Practical Application Examples}

5.2.1 GM survey instruments (Eberline E-140 and Bicron Surveyor $X$ ) used in conjunction with a GM pancake probe can be used as an indicator of when increased radiation fields are present.

Example: Removal of components or samples from waste pits and tanks. Method: The instrument is placed in the vicinity of riser or pit with the GM probe facing the area to be measured and the audible response or meter indication positioned for remote monitoring (a walking stick could be used to facilitate positioning). The increased count rate indication audible or visual can be used to prompt follow-up measurements with an lon chamber to measure dose rates and establish appropriate posting and access.

Limitations: 1-Noise interference, 2-Positioning is critical if remote viewing with optics is used, 3- The cord length is limited to the standard cord provided by PNNL, a longer cord would require a special calibration per Section 4.1.2 above.

\footnotetext{
${ }^{2}$ LMHC Extent of Condition Corrective Action Plan, Aug 1999
} 
5.2.2 The Bicron Micro Rem Meter can be used to detect minute increases in radioactivity and levels of radiation fields to monitor process activities.

Example: Monitoring of bore hole drilling process activities to determine adequate radiological controls.

Method: The instrument is placed at the edge of the drill casing to monitor bore hole split spoon samples during removal from casing to provide first indication of activity levels and subsequent determination of adequate radiological controls. In addition, it can be used to monitor the cyclone separator sample sock and waste drum. This keeps the worker out of the drill rig operating areas and confinement tent via remote optics monitoring. Limitations: 1-Positioning is critical due to remote viewing with optics, 2- Positioning must accommodate the process to be effective. (Limited locations, must be securely fastened due movement of large equipment). 3- Detection is affected by attenuation of split spoon and sample casing.

5.2.3 The Eberline RO-7 Ion Chamber can be used in conjunction with up to 500 feet of extension cable to monitor radiation dose rates.

Example: Monitoring of dose rates within waste pits and tanks, process monitoring for Air Lift Circulator and Above Ground Transfer System operations.

Method: The detector is placed in the vicinity of the ventilation or transfer system, connected to remote cabling and then to remote area for connection to the instrument. Note: This specific instrument use is validated by the HIEC and these results are valid quantitative results as long as the daily functional check is current.

Limitations: 1-Instrument has a limited lower range of detection conversely it has a very broad high range up to $20 \mathrm{~K} \mathrm{Rad} / \mathrm{hr}$ if the high range probe is used. 2-Different probes are necessary to take advantage of diverse range. 3-May not be ALARA to re enter area to function check probe in the field. 4- Must verify "zero calibrated" annotation on detector and body to be used.

5.2.4 The SAIC PD-31 ${ }^{3}$. Electronic Dosimeter and SAIC PDE-4 ${ }^{4}$. RadStar 5 . TeleDosimetry System can be used to continuously monitor in-process dose rates.

Example: Monitoring of areas around work area during pit and Riser work for continuous monitoring of personal dose rate fields.

Method: The dosimeter (PD3I) can be placed on head to determine the areas of shine from open risers and pits. The radio-dosimeters can be used for continuous monitoring of worker exposure rates to ensure time in high dose areas is minimized.

Limitations: 1-Settings are fixed and can not be adjusted in the field. 2-Detection capabilities are limited with these dosimeters. 3-Radio-Field and static interference has been noted in the PDE-4.

\footnotetext{
${ }^{3} \mathrm{PD}-3 \mathrm{i}$ is a trademark of Science Applications International Corporation (SAIC)

${ }^{4}$ PDE-4 is a trademark of SAIC

${ }^{5}$ RadStar is a trademark of SAIC
} 


\subsection{Conclusion}

The applications of remote monitoring capabilities presented in this document are currently in use at many RPP facilities with no significant safety impact on workers or the environment. The information presented here establishes a formal approach for practical implementation of remote continuous dose rate monitoring and relates the potential positive impacts for dose reduction and ALARA principles.

\subsection{References}

- Lockheed Martin Hanford Corporation (LMHC) Extent of Condition Corrective Action Plan, August 17, 1999, M. P. Delozier

- Completed Decision Making Package, TBTN: INGH-9503-RLS-0016, D. B. Ottley, 1994

- 10 CFR 835, Occupational Radiation Protection, November 4, 1998

- DOE/EH-0256T, U.S. Department of Energy Radiological Control Manual, Rev. 1 , April 1994

- Hanford Site Radiological Control Manual, HSRCM-1, Rev. 2, December 1994 


\section{DISTRIBUTION SHEET}

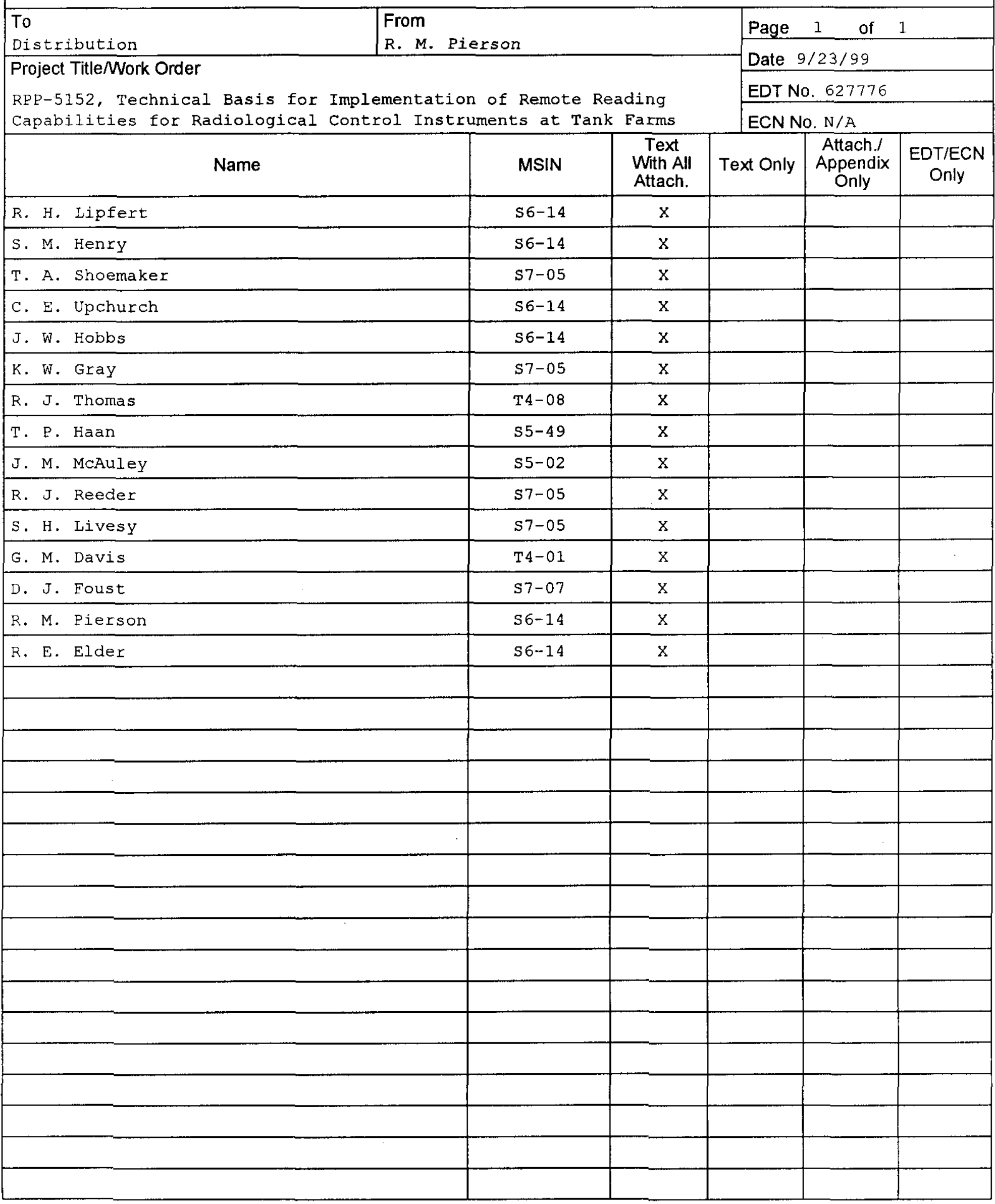

